\title{
CLASSIFICAÇÃO TECNOLÓGICA DE SOLOS E RESÍDUOS INDUSTRIAIS, COM E SEM TRATAMENTO TÉRMICO, PARA FINS RODOVIÁRIOS ${ }^{1}$
}

\author{
Carlos Cardoso Machado 2 , Dalila Campos de Medeiros Fernandes ${ }^{3}$, Reginaldo Sérgio Pereira ${ }^{4}$, Giovanni Levy \\ Santanna ${ }^{4}$, Dario Cardoso de Lima ${ }^{5}$ J José Maurício Machado Pires ${ }^{6}$
}

\begin{abstract}
RESUMO - Estudou-se o comportamento mecânico das misturas solo-alcatrão, solo-cal-alcatrão e solo-cimentoalcatrão, com base nos ensaios de limites de liquidez e plasticidade, CBR, compressão simples e permeabilidade, visando a aplicabilidade destas em rodovias. Trabalhou-se com três amostras de solos (ETA, NV e VS), representativos das ocorrências da microrregião de Viçosa-MG. Foram empregados alcatrão, nos quantitativos de $0,25,0,5,1,2,4$ e $6 \%$, cal hidratada e cimento Portland, em conjunto com o alcatrão, na dosagem de $2 \%$, considerando-se a energia do ensaio de compactação AASHTO Normal. A adição de alcatrão reduziu significativamente os valores de LL dos solos, mas com pouca variação nos valores de IP. Conclui-se que o alcatrão contribuiu para melhorar as características mecânicas e hidráulicas dos solos, para alguns tratamentos, não atingindo, entretanto, os padrões de resistência mecânica exigida pelo DNER para camadas de sub-base de pavimentos flexíveis. Quanto às misturas solo-cal-alcatrão e solo-cimento-alcatrão, constatou-se melhoria substancial nos parâmetros de resistência mecânica em relação aos solos, principalmente devido à ação cimentante da cal e do cimento, e que para alguns tratamentos esta ação foi potencializada pelo alcatrão, incidindo em resistência mecânica superior à das misturas solo-cal e solo-cimento. $\mathrm{O}$ alcatrão, em alguns tratamentos, ocasionou decréscimos na permeabilidade das misturas, com relação ao solo, de até dez vezes. $\mathrm{O}$ alcatrão mostrou ser um estabilizante de interesse para fins rodoviários apenas para determinadas condições, envolvendo tipo de solo e tipo e teor de alcatrão, o que indica que estudos nesta direção devem apresentar uma característica regional.
\end{abstract}

Palavras-chave: Estradas florestais, misturas solo-alcatrão, solo-cal-alcatrão, solo-cimento-alcatrão e características mecânicas e hidráulicas.

\section{TECHNOLOGICAL CLASSIFICATION OF SOILS AND INDUSTRIAL RESIDUES WITH AND WITHOUT THERMAL TREATMENT FOR FOREST ROAD PAVEMENT}

\begin{abstract}
The behavior of the mechanical mixtures soil-wood tar, soil-lime-wood tar and soil-cement-wood tar, based on the Atterberg limits California Bearing Ratio (CBR), Unconfined Compression Strength (UCS) and permeability, were studied for application in forest road pavement. Three soil samples of (ETA, NV and VS) representative of Viçosa-MG occurrences were used. Wood-tar was used 0.25, 0.5, 1, 2, 4 and 6\% and lime and cement mixture.The addition of wood-tar reduced the Atterberg values significantly. It was concluded that wood-tar improved the mechanical and hydraulic characteristics of the soils, for some treatments without, however, reaching however, the patterns of mechanical resistance demanded by DNER sub-base layers of flexible pavements. Regarding the mixtures soil-lime-wood tar and soil-cement-wood tar, substantial improvement was verified in the mechanical resistance parameters in relation to the soils, mainly due to the action of lime and cement. This action was found to be stronger for the wood tar in some treatments, leading to a higher mechanical resistance than that of the mixtures soil-lime and soil-cement. Wood tar caused a decrease in mixture permeability in relation to the soil up to 10 times. Wood tar was found to be an important stabilizer only for some forest road pavement conditions, involving soil type, and wood tar type and level, suggesting that studies on this area should present a regional characteristic.
\end{abstract}

Key words: Forest road, soil-wood tar mixtures, CBR, UCS, and mechanic and hydraulic characteristics.

1 Recebido para publicação em 17.7.2002.

Aceito para publicação em 9.9.2003.

2 Professor Titular do Departamento de Engenharia Florestal da Universidade Federal de Viçosa, 36570-000 Viçosa-MG; ${ }^{3}$ Bolsista Pós-doutorada do CNPq/UFV; ${ }^{4}$ Doutorando em Ciência Florestal - UFV; ${ }^{5}$ Professor Titular do Departamento de Engenharia Civil - UFV; ${ }^{6}$ Doutorando em Ciência Florestal - UFV. 


\section{INTRODUÇÃO}

A busca por materiais alternativos para uso na construção de pavimentos rodoviários justifica-se pelo fato de o setor rodoviário ser responsável por mais de $70 \%$ das cargas transportadas no Brasil, bem como por existir cerca de 1,7 milhão de quilômetros de estradas públicas vicinais. Associa-se a isto a necessidade de que as rodovias sejam trafegáveis durante todo o ano, com qualidade e maior segurança, diminuindo assim o número excessivo de acidentes nas estradas e os danos à frota nacional de veículos e ao meio ambiente. Estas constatações abrem um campo amplo para a busca de materiais alternativos, de baixo custo e elevado desempenho; e para a construção de pavimentos rodoviários, garantindo resistência mecânica e uma vida útil mais longa dos pavimentos. Uma solução tecnológica poderá ser a aplicação de resíduos industriais como aditivos químicos para melhorar as características geotécnicas dos solos, o que é essencial para solucionar a problemática da pavimentação para muitas regiões brasileiras, em geral cobertas por solos de baixa resistência mecânica, bem como para garantir a retirada dos resíduos industriais, muitas vezes poluentes, do meio ambiente e confiná-los em condições controladas na estrutura das rodovias.

O estado-da-arte da estabilização química, utilizando resíduos industriais, é recente em todo mundo. No Brasil, em termos práticos, esta técnica tem sido processada via o emprego do cimento (misturas solo-cimento) e esporadicamente com o emprego da cal (mistura solocal), assim como betumes: asfaltos e alcatrões para pavimentação, sendo os asfaltos (misturas solo-emulsão asfáltica) mais usados. Quanto aos alcatrões para pavimentação, seu uso tem sido muito restrito no País.

Os produtos tradicionalmente utilizados elevam o custo da pavimentação, tornando-os inviáveis para o setor florestal. Considerando que no Brasil existe uma enorme carência de solos naturalmente adequados para a construção das camadas que constituem as estruturas das rodovias, em especial as vicinais, que representam mais de $90 \%$ da malha nacional, segundo os órgãos rodoviários nacionais (DNER e DERs) fica evidente a necessidade da aplicação de procedimentos que visam melhorar os parâmetros resistência ao cisalhamento, deformação sob a ação de cargas, permeabilidade etc., destacandose a estabilização química.

O objetivo do trabalho foi apresentar os resultados de estudos realizados na UFV sobre a aplicação do alcatrão de madeira de eucalipto na estabilização de solos para pavimentação de estradas florestais, abordando: a) o desempenho da estabilização de solos residuais com o alcatrão de madeira; b) o comportamento da mistura soloalcatrão na presença da cal hidratada e do cimento Portland; c) o efeito de alcatrões tratados termicamente nas propriedades dos solos: limites de liquidez, resistência mecânica, capacidade de suporte e permeabilidade; e d) a determinação, em laboratório, do teor ótimo de alcatrão para estabilização química de solos com fins rodoviários, considerando-se a resistência mecânica, a capacidade de suporte e a permeabilidade.

\section{MATERIAL DE MÉTODOS}

\subsection{Materiais}

\subsubsection{Solos}

Foram analisadas três amostras de solos, provenientes da região de Viçosa, Minas Gerais. No Quadro 1 estão as informações sobre a formação pedológica, o horizonte e a profundidade de coleta das amostras.

Quadro 1 - Descrição das amostras de solos e profundidade de coleta

Table 1 -Description of soil samples and collection depth

\begin{tabular}{|c|l|c|c|}
\hline $\begin{array}{c}\text { Amostra de } \\
\text { Solo }\end{array}$ & \multicolumn{1}{|c|}{$\begin{array}{c}\text { Formação } \\
\text { Pedológica }\end{array}$} & Horizonte & $\begin{array}{c}\text { Profundidade de } \\
\text { Coleta }(\mathrm{m})\end{array}$ \\
\hline ETA & Latossolo & B & 6,20 \\
NV & Latossolo & B & 4,30 \\
VS & Saprolítico & C & 15,70 \\
\hline
\end{tabular}

Fonte: Nogami \& Villibor (1995).

ETA - localizado próximo à usina de asfalto da Prefeitura Municipal de Viçosa-MG; NV - localizado no Bairro de Nova Viçosa - ViçosaMG; e VS - localizado na Vila Secundino da UFV - Viçosa -MG.

\subsubsection{Estabilizantes}

Os agentes estabilizantes empregados foram:

- alcatrão de madeira de eucalipto no estado natural e após o tratamento térmico às temperaturas de 110, 170 e $210^{\circ} \mathrm{C}$, segundo o croqui esquemático apresentado na Figura 1;

- cal hidratada da categoria CH-I, da indústria de calcinação ICAL (supercal), cuja caracterização química está no Quadro 2; e 
- cimento Portland CP-II-E 32, da marca Barroso, cuja análise química está apresentada no Quadro 3.

\subsection{Métodos}

Analisou-se o comportamento das misturas soloalcatrão, solo-cal-alcatrão e solo-cimento-alcatrão, produzidas com diferentes doses, tipos de alcatrão e período de cura, com vistas à aplicabilidade em camadas de pavimentos rodoviários flexíveis. Foram realizados os seguintes ensaios: a) análise granulométrica das amostras de solos; b) ensaios de limite de liquidez e de plasticidade; c) moldagem de corpos-de-prova na energia de compactação do ensaio AASHTO Normal; d) corpos-de-prova das misturas moldados nos teores de alcatrão, cal e cimento; e) ensaios de compressão não-confinada; e f) ensaios CBR.

\section{RESULTADOS E DISCUSSÃO}

\subsection{Caracterização Geotécnica das Amostras de Solos}

No Quadro 4 e na Figura 2 estão apresentadas, respectivamente, a caracterização geotécnica e as curvas granulométricas das amostras analisadas no presente trabalho.

O Quadro 5 introduz a classificação dos solos, segundo o sistema recomendado pela HRB, e também os dados de compactação, CBR, expansão medida no ensaio CBR e permeabilidade das amostras analisadas.

Os solos em estudo são classificados, de acordo o HRB, como materiais suscetíveis de serem empregados em subleitos de estradas, prevendo-se para as amostras

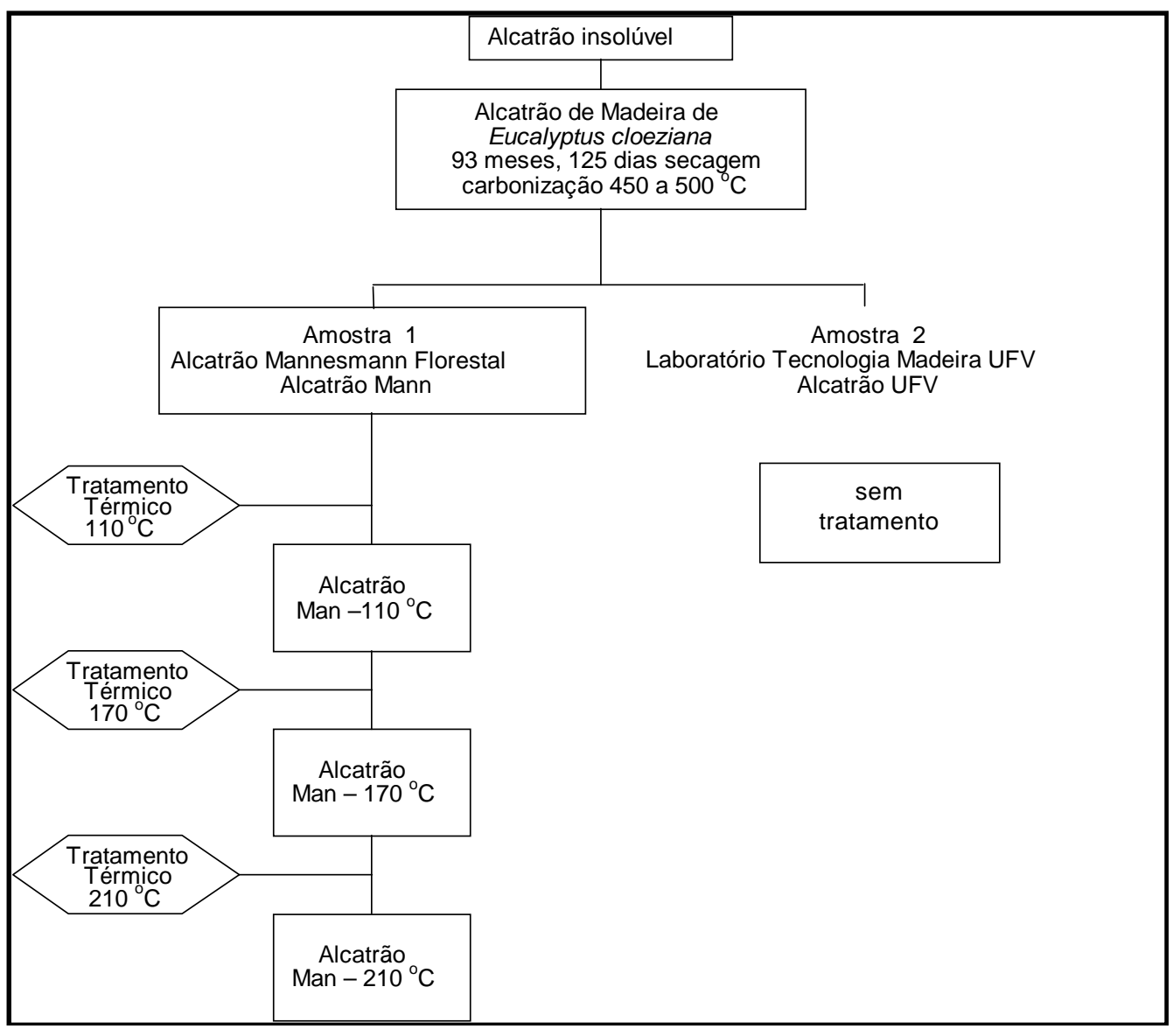

Figura 1 - Croqui esquemático representando os tipos de alcatrão empregados.

Figure 1-Types of wood tar used. 
Quadro 2 - Caracterização química da cal cálcica hidratada $\mathrm{CH}-\mathrm{I}$

Table 2 - Chemical characterization of (hydrated) lime $\mathrm{CH}-\mathrm{I}$

\begin{tabular}{|l|c|}
\hline Componente & Teor Médio (\%) \\
\hline $\mathrm{CaO}$ & 74,0 \\
\hline $\mathrm{MgO}$ & 0,70 \\
\hline $\mathrm{SiO}_{2}$ & 1,50 \\
\hline $\mathrm{Perda}$ por calcinação & 22,0 \\
\hline $\mathrm{CaO}$ disponível & 70,0 \\
\hline $\mathrm{Ca}(\mathrm{OH})_{2}$ disponível & 92,0 \\
\hline $\mathrm{CaO}$ na base nâno-volátil & 92,0 \\
\hline $\mathrm{CaO}$ não-hidratado máximo & 1,00 \\
\hline Umidade em excesso máxima & 1,00 \\
\hline
\end{tabular}

Fonte: Ferraz (1994).

Quadro 3 - Composição química do cimento Portland, CPII-E 32

Table 3 - Chemical composition of the Portland cement, CP-II-E 32

\begin{tabular}{|c|c|}
\hline Componente & Teor médio (\%) \\
\hline $\mathrm{SiO}_{2}$ & 21,87 \\
\hline $\mathrm{Al}_{2} \mathrm{O}_{3}$ & 5,65 \\
\hline $\mathrm{Fe}_{2} \mathrm{O}_{3}$ & 3,22 \\
\hline $\mathrm{CaO}$ & 57,29 \\
\hline $\mathrm{MgO}$ & 2,68 \\
\hline $\mathrm{SO}_{3}$ & 2,89 \\
\hline $\mathrm{K}_{2} \mathrm{O}$ & 0,71 \\
\hline $\mathrm{Cal}$ livre & 1,57 \\
\hline
\end{tabular}

Fonte: Ferraz (1994).

ETA e NV, por se enquadrarem no grupo A-7 (solos argilosos), com índices de grupo de 16 e 10, respectivamente, um comportamento como material de subleito, de fraco a pobre; e para a amostra VS, por se enquadrar no grupo A-2-4 e possuir índice de grupo 0 (solos granulares), um comportamento de excelente a bom.

\subsection{Avaliação do Efeito dos Aditivos em Relação aos Critérios de Projetos de Rodovias}

Analisou-se o efeito dos aditivos nos parâmetros limite de liquidez, índice de plasticidade (IP), CBR, compressão simples, expansibilidade (medida no ensaio CBR) e coeficiente de permeabilidade dos solos, com vistas à aplicabilidade das misturas solo-alcatrão, solo-cal-alcatrão

R. Árvore, Viçosa-MG, v.27, n.5, p.657-668, 2003 e solo-cimento-alcatrão em diferentes doses, tipos de alcatrão e período de cura, em camadas de pavimentos rodoviários, segundo as exigências do DNER.

\subsubsection{Limites de Atterberg}

Observou-se que a adição dos alcatrões nas dosagens estudadas alterou os valores de LL dos solos, sendo maior o efeito sobre os solos argilosos, reduções estas também dependentes do tipo de alcatrão.

Os valores de LL observados para as misturas soloalcatrão-Mann variaram na faixa de 82 a $72 \%$ e 78 a $69 \%$, respectivamente, para os solos ETA e NV, sendo maiores que os obtidos para as misturas solo-alcatrão Man-170, na faixa de 77 a $50 \%$ e 64 a $57 \%$, para os mesmos solos. Esses dados ressaltam o maior efeito do alcatrão Man-170 sobre a capacidade de absorver água dos dois solos, que, apesar de não atenderem às especificações do DNER para camadas de base (LL $\leq 25 \%)$, tiveram redução significativa nos seus valores de LL.

\subsubsection{CBR e Expansão}

Os solos ETA, NV e VS, no estado natural, apresentam valores de CBR de 12,7, 10 e 13,6\%, respectivamente. $\mathrm{O}$ efeito dos diferentes tipos de alcatrão sobre as características mecânicas desses solos pode ser comprovado ao comparar os valores de CBR referentes aos solos naturais e às misturas solo-alcatrão. Observa-se que todos os solos foram reativos às dosagens de alcatrão utilizadas, nos períodos de cura de 1 e 28 dias (Figuras 3 e 4, respectivamente), resultando, em alguns tratamentos, em valores superiores ao dos solos naturais. Pode-se também observar efeito diferenciado entre os alcatrões. Os melhores resultados para as misturas solo-alcatrão foram obtidos com o alcatrão Man-170, após 28 dias de cura, conforme pode ser constatado no Quadro 6.

Considerando os critérios do DNER (SENÇO, 1997) para camadas de base de pavimentos ( $C B R \geq 60 \%$ ), podese afirmar que estes índices, para os solos e as misturas solo-alcatrão estudadas, estão bem abaixo e não satisfazem às exigências mínimas para esta utilização. Quanto à aplicação como sub-base de pavimentos (IS ou CBR $\geq 20 \%$ ), também observa-se aqui que nenhuma das misturas atende à recomendação do DNER. Podese inferir que as misturas obtidas com o solo ETA com $0,25 \%$, NV com $0,5 \%$ e VS com $1 \%$ do alcatrão Man-170, após 28 dias de cura, são as que mais se aproximaram das exigências do DNER. 
Quadro 4 - Granulometria, limites de Atterberg e peso específico dos sólidos

Table 4 - Granulometry, Atterberg limits and specific weight of solids

\begin{tabular}{|c|c|c|c|c|c|c|c|c|}
\hline $\begin{array}{c}\text { Amostra de } \\
\text { Solo }\end{array}$ & Argila & Silte & Areia & $\begin{array}{c}\text { Diâmetro } \\
<0,074 \mathrm{~mm}\end{array}$ & LL & LP & IP & $\begin{array}{c}\text { Peso Específico dos } \\
\text { Sólidos }\left(\mathrm{kN} / \mathrm{m}^{3}\right)\end{array}$ \\
\hline \multicolumn{7}{|c|}{$(\%)$} \\
\hline ETA & 60 & 12 & 28 & 78,30 & 75 & 45 & 29 & 27,63 \\
\hline NV & 68 & 4 & 28 & 78,80 & 67 & 48 & 23 & 27,62 \\
\hline VS & 15 & 11 & 74 & 28,89 & 27 & 17 & 10 & 27,01 \\
\hline
\end{tabular}

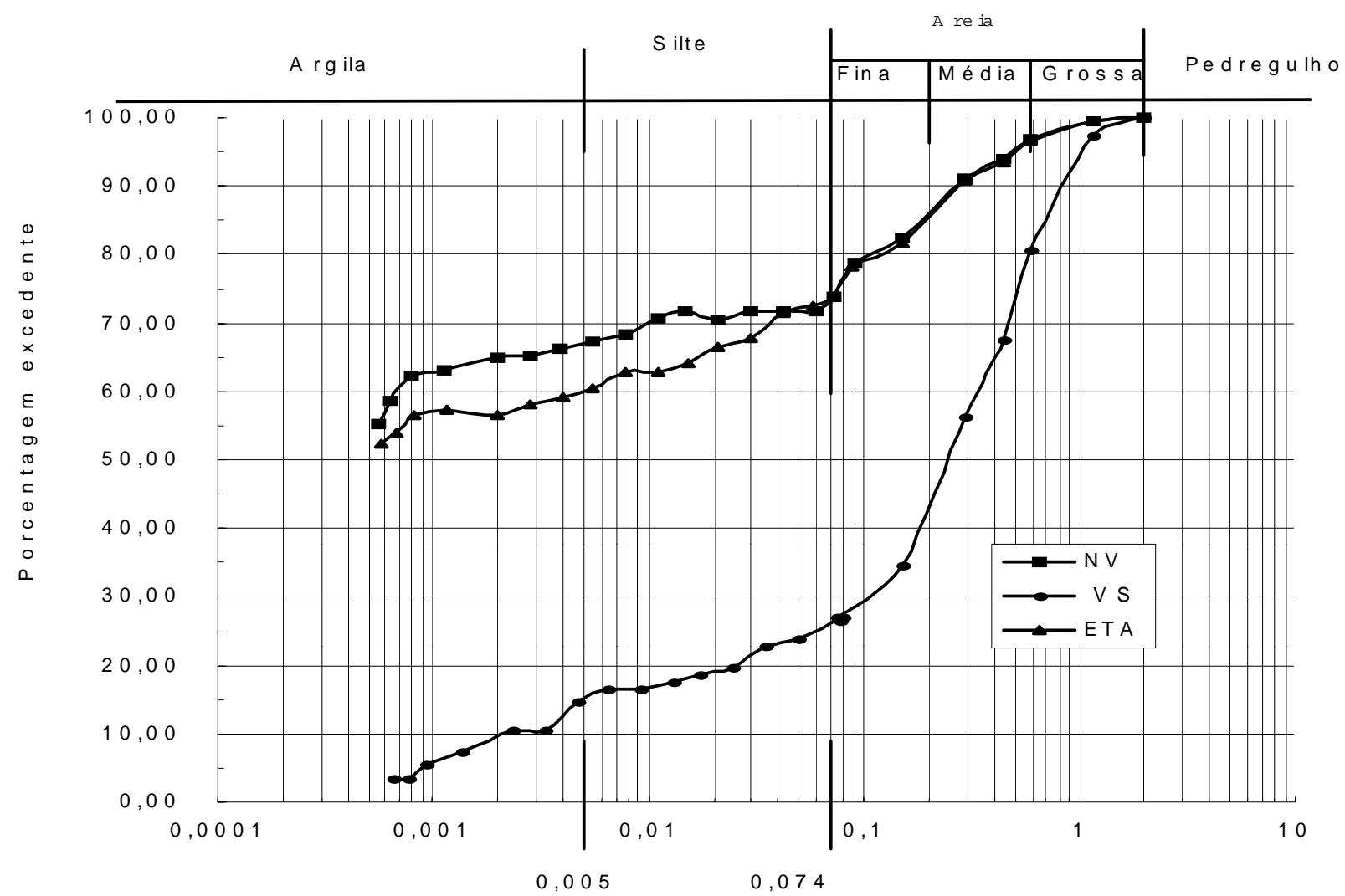

Diâmetro (mm)

Figura 2 - Curvas granulométricas das amostras de solos. Figure 2-Granulometric curves of the soil samples.

A adição de $2 \%$ de cal ou cimento elevou os valores de CBR dos solos ETA, NV e VS, após 28 dias de cura, respectivamente, para 17, 27 e 91\% (nas misturas solocal) e para 35,31 e $70 \%$ (nas misturas solo-cimento). Constata-se, pois, que os valores referentes às misturas solo NV-cal, ETA-cimento e NV-cimento são superiores aos especificados para camadas de sub-bases de pavimentos, e os referentes às misturas VS-cal e VScimento suplantam os especificados para camadas de bases de pavimentos, segundo as exigências do DNER. 
Quadro 5 - Classificação das amostras de solos e resultados dos ensaios de compactação, CBR, expansãocBR e permeabilidade

Table 5 - Classification of the soil samples and results of the compaction, CBR, expansion CBR and permeability assays

\begin{tabular}{|c|c|c|c|c|c|c|}
\hline \multirow{2}{*}{ Amostras } & \multirow{2}{*}{ HRB } & $\mathrm{Y}_{\mathrm{ds}}$ & $\mathrm{W}_{\mathrm{ot}}$ & CBR & Expansão $_{\mathrm{CBR}}$ & \multirow{2}{*}{$\frac{\text { Permeabilidade }}{\mathrm{K}_{20}(\mathrm{~cm} / \mathrm{s})}$} \\
\hline & & $\left(\mathrm{Kgf} / \mathrm{cm}^{3}\right)$ & \multicolumn{3}{|c|}{$(\%)$} & \\
\hline ETA & A-7-5 (16) & 1,38 & 31,8 & 12,7 & 0,17 & $2,382^{-6}$ \\
\hline $\mathrm{NV}$ & A-7-5 (10) & 1,418 & 30,4 & 10,0 & 0,17 & $7,375^{-7}$ \\
\hline VS & A-2-4 (0) & 1,81 & 14,0 & 14,0 & 0,50 & $3,524^{-6}$ \\
\hline
\end{tabular}

Quadro 6 - Melhores resultados dos ensaios de CBR - misturas solo- alcatrão Man-170 Table 6 - Best CBR assay results - soil-Man-170 wood tar mixtures

\begin{tabular}{|c|c|c|c|c|c|}
\hline \multirow{2}{*}{ Amostra de solo } & \multirow{2}{*}{ Alcatrão (\%) } & \multicolumn{2}{|c|}{ CBR $(\%)$} & \multicolumn{2}{|c|}{ Expansão (\%) } \\
\hline & & Cura de 1 dia & Cura de 28 dias & Cura de 1 dia & Cura de 28 dias \\
\hline \multirow{5}{*}{ ETA } & Natural & 12,74 & - & 0,177 & \\
\hline & 0,25 & 11,24 & 18,30 & 0,136 & 0,019 \\
\hline & 0,50 & 9,47 & 16,37 & 0,101 & 0,019 \\
\hline & 1,0 & 12,59 & 17,41 & 0,126 & 0,016 \\
\hline & 2,0 & 10,74 & 17,01 & 0,130 & 0,240 \\
\hline \multirow{5}{*}{ NV } & Natural & 10,09 & - & 0,176 & - \\
\hline & 0,25 & 11,21 & 12,90 & 0,158 & 0,175 \\
\hline & 0,50 & 14,13 & 19,26 & 0,146 & 0,130 \\
\hline & 1,0 & 10,75 & 14,45 & 0,194 & 0,211 \\
\hline & 2,0 & 6,21 & 9,2 & 0,176 & 0,070 \\
\hline \multirow{5}{*}{ VS } & Natural & 13,66 & - & 0,507 & - \\
\hline & 0,25 & 11,73 & 12,37 & 0,446 & 0,104 \\
\hline & 0,50 & 11,95 & 14,91 & 0,459 & 0,159 \\
\hline & 1,0 & 14,38 & 17,76 & 0,492 & 0,124 \\
\hline & 2,0 & 11,10 & 15,22 & 0,451 & 0,131 \\
\hline
\end{tabular}

A adição de alcatrões às misturas solo-cal e solocimento levou a respostas diferenciadas do parâmetro CBR, no que tange ao período de cura e tipo de alcatrão utilizado. Neste caso, conforme se infere da Figura 5 e dos Quadros de 7 a 9, apenas o alcatrão Mann mostrouse efetivo em aumentar os valores de CBR das misturas solo-cimento, para os solos ETA e NV e períodos de cura de 1 e 28 dias, e solo-cal, para o solo ETA e ambos os períodos de cura. Estes resultados indicam a aplicação das seguintes misturas como:

- materiais de sub-base de pavimentos rodoviários flexíveis: solo ETA-cal, com 0,5 e $2 \%$ de alcatrão Mann; solo VS-cal, com 0,25 e $0,5 \%$ de alcatrão Mann; solo ETA-cimento, exceto com $6 \%$ de alcatrão Mann; e solo VS-cimento, exceto a partir da dosagem de $2 \%$ de alcatrão Mann; e

- materiais de base: VS-cimento, com $0,5 \%$ de alcatrão Mann.

Vale destacar que para locais onde haja carência de materiais e o período do projeto corresponda a um número de operações do eixo-padrão, de 8,2 toneladas igual ou inferior a $10^{6}$, o DNER permite que se empreguem, em camadas de base, materiais com CBR $\geq 40 \%$ (SENÇO, 1997). Para esta situação, observa-se que as misturas solo VS-cal com $0,25 \%$ de alcatrão Mann, ETA-cimento com 0,25 e $0,5 \%$ de alcatrão Mann, NV-cimento com 2 e 4,0\% de alcatrão Mann e solo VS-cimento com 0,25 e $0,5 \%$ de alcatrão Mann, após 28 dias, podem ser empregadas como camadas de base de pavimentos rodoviários flexíveis. 


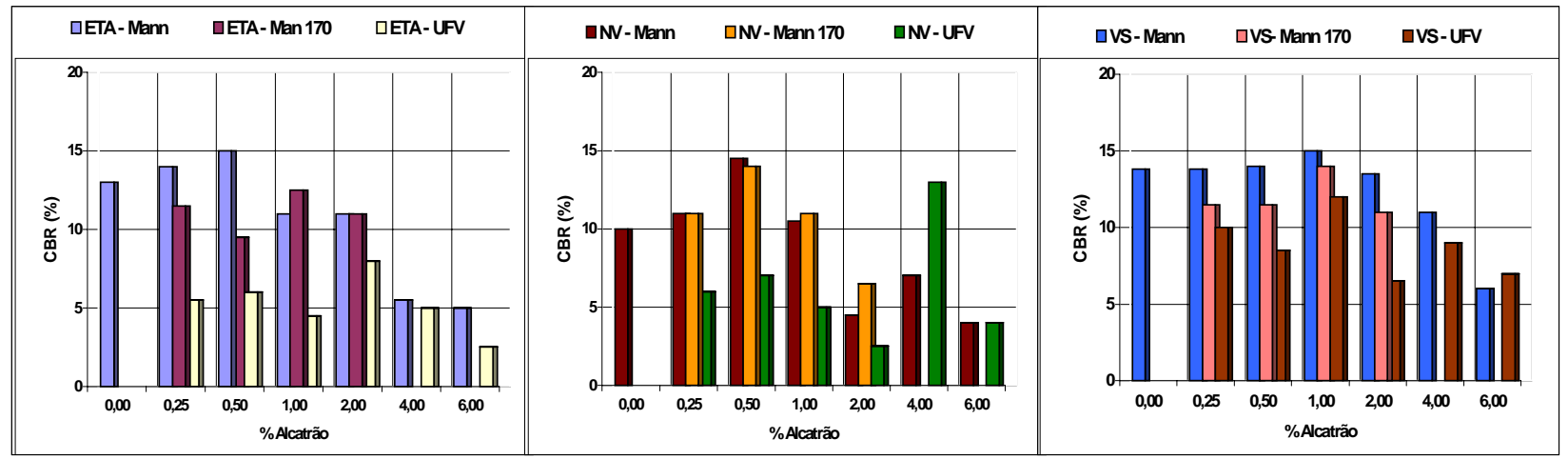

Figura 3 - Índices CBR para solo natural e misturas solo-alcatrão, com diferentes dosagens e tipos de alcatrão para períodos de cura de 1 dia.

Figure 3 - CBR indices for natural soil and soil-wood tar mixtures, with diffrent dosages and types of wood tar for 1-day curing periods.

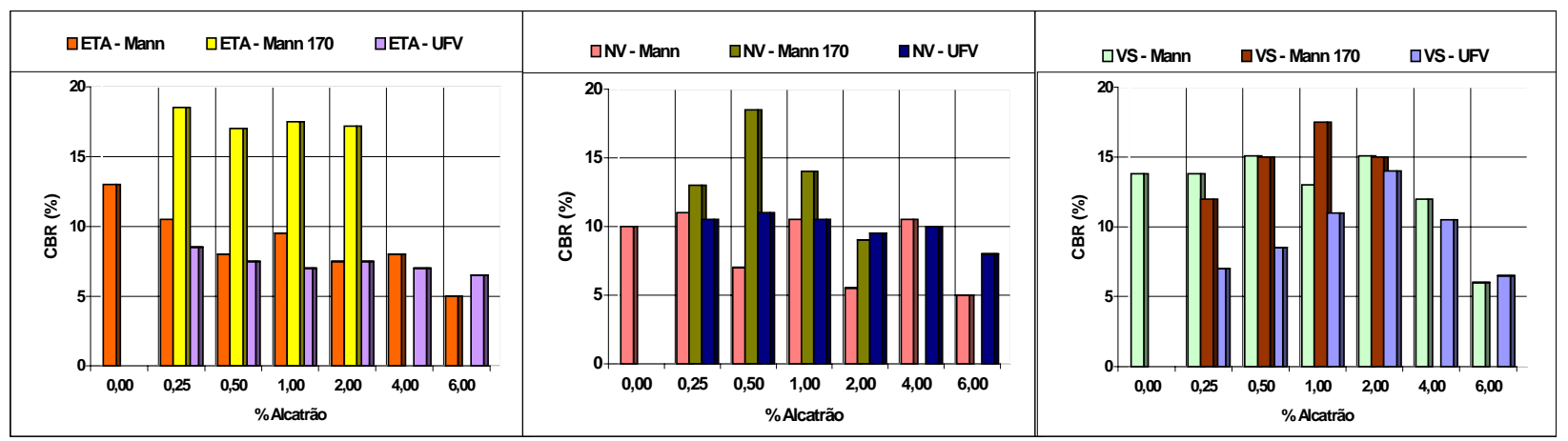

Figura 4 - Índices CBR para solo natural e misturas solo-alcatrão, com diferentes dosagens e tipos de alcatrão para períodos de cura de 28 dias.

Figure 4-CBr indices for natural soil and soil-wood tar mixtures, with different dosages and types of wood tar for 28-day curing.

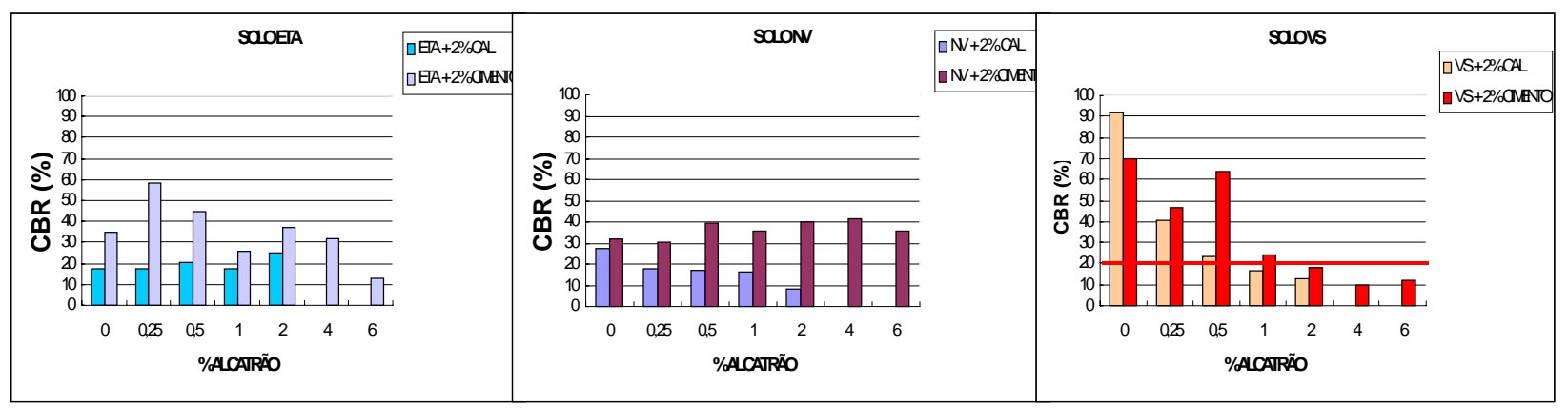

Figura 5 - Índices CBR para solo natural e misturas solo-cal-alcatrão e solo-cimento-alcatrão Mann de cura de 28 dias. Figure 5-CBR indices for natural soil and soil-lime-tar and soil-cement-wood tar mixtures for 28-day curing period. 
Quadro 7 - Resultados dos ensaios de CBR para solo natural e misturas solo-alcatrão Mann Table 7 - CBR assay results for soil and soil-mann wood tar mixtures

\begin{tabular}{|c|c|c|c|c|c|}
\hline \multirow{2}{*}{ Amostra de Solo } & \multirow{2}{*}{ Alcatrão } & \multicolumn{2}{|c|}{ CBR $(\%)$} & \multicolumn{2}{|c|}{ Expansão (\%) } \\
\hline & & Cura de 1 dia & Cura de 28 dias & Cura de 1 dia & Cura de 28 dias \\
\hline \multirow{7}{*}{ ETA } & Natural & 12,74 & - & 0,177 & - \\
\hline & 0,25 & 14,33 & 10,44 & 0,068 & 0,129 \\
\hline & 0,50 & 14,69 & 7,43 & 0,044 & 0,127 \\
\hline & 1,0 & 10,49 & 9,56 & 0,069 & 0,148 \\
\hline & 2,0 & 10,62 & 7,11 & 0,070 & 0,128 \\
\hline & 4,0 & 5,37 & 8,16 & 0,041 & 0,131 \\
\hline & 6,0 & 5,17 & 4,90 & 0,061 & 0,128 \\
\hline \multirow{7}{*}{ NV } & Natural & 10,09 & - & 0,176 & - \\
\hline & 0,25 & 11,50 & 11,585 & 0,072 & 0,104 \\
\hline & 0,50 & 14,69 & 7,220 & 0,047 & 0,042 \\
\hline & 1,0 & 10,62 & 10,617 & 0,073 & 0,151 \\
\hline & 2,0 & 4,42 & 5,308 & 0,070 & 0,081 \\
\hline & 4,0 & 7,43 & 10,617 & 0,041 & 0,109 \\
\hline & 6,0 & 4,25 & 4,77 & 0,059 & 0,059 \\
\hline \multirow{7}{*}{ VS } & Natural & 13,66 & - & 0,507 & - \\
\hline & 0,25 & 13,90 & 13,867 & 0,146 & 0,211 \\
\hline & 0,50 & 14,39 & 15,500 & 0,230 & 0,240 \\
\hline & 1,0 & 14,88 & 13,401 & 0,220 & 0,255 \\
\hline & 2,0 & 14,15 & 15,499 & 0,290 & 0,171 \\
\hline & 4,0 & 10,96 & 11,42 & 0,3400 & 0,109 \\
\hline & 6,0 & 5,82 & 5,85 & 0,230 & 0,069 \\
\hline
\end{tabular}

Quadro 8 - Resultados dos ensaios de CBR para solo-natural e misturas solo-cal-alcatrão Mann Table 8-CBR assay results for natural soil and mann soil-lime-wood tar mixtures

\begin{tabular}{|c|c|c|c|c|c|c|}
\hline \multirow{2}{*}{ Amostra de solo } & \multirow{2}{*}{ Cal } & \multirow{2}{*}{ Alcatrão } & \multicolumn{2}{|c|}{ CBR $(\%)$} & \multicolumn{2}{|c|}{ Expansão (\%) } \\
\hline & & & Cura de 1 dia & Cura de 28 dias & Cura de 1 dia & Cura de 28 dias \\
\hline \multirow{6}{*}{ ETA } & & Natural & 12,74 & - & 0,177 & \\
\hline & 2 & 0 & 29,02 & 17,25 & 0,009 & 0,017 \\
\hline & 2 & 0,25 & 16,78 & 17,34 & 0,059 & 0,026 \\
\hline & 2 & 0,5 & 21,95 & 20,35 & 0,032 & 0,017 \\
\hline & 2 & 1,0 & 13,75 & 17,71 & 0,058 & 0,032 \\
\hline & 2 & 2,0 & 17,87 & 24,77 & 0,029 & 0,013 \\
\hline \multirow{6}{*}{ NV } & & Natural & 10,09 & - & 0,176 & - \\
\hline & 2 & 0 & 25,66 & 27,43 & 0,042 & 0,031 \\
\hline & 2 & 0,25 & 26,37 & 17,52 & 0,031 & 0,049 \\
\hline & 2 & 0,5 & 20,35 & 17,34 & 0,078 & 0,038 \\
\hline & 2 & 1,0 & 22,30 & 16,10 & 0,093 & 0,017 \\
\hline & 2 & 2,0 & 19,23 & 8,49 & 0,079 & 0,022 \\
\hline \multirow{6}{*}{ VS } & & Natural & 13,66 & - & 0,507 & - \\
\hline & 2 & 0 & 44,63 & 91,67 & 0,026 & 0,032 \\
\hline & 2 & 0,25 & 41,95 & 40,67 & 0,031 & 0,026 \\
\hline & 2 & 0,5 & 15,38 & 23,42 & 0,078 & 0,018 \\
\hline & 2 & 1,0 & 19,11 & 16,32 & 0,088 & 0,017 \\
\hline & 2 & 2,0 & 22,26 & 12,59 & 0,045 & 0,017 \\
\hline
\end{tabular}


Quadro 9 - Resultados dos ensaios de CBR para solo natural e misturas solo-cimento-alcatrão Mann Table 9 - CBR assay results for natural soil and soil-cement-wood tar mixtures

\begin{tabular}{|c|c|c|c|c|c|c|}
\hline \multirow{2}{*}{ Amostra de Solo } & \multirow{2}{*}{ Cimento } & \multirow{2}{*}{ Alcatrão } & \multicolumn{2}{|c|}{$\operatorname{CBR}(\%)$} & \multicolumn{2}{|c|}{ Expansão (\%) } \\
\hline & & & Cura de 1 dia & Cura de 28 dias & Cura de1 dia & Cura de 28 dias \\
\hline \multirow{8}{*}{ ETA } & & Natural & 12,74 & - & 0,177 & 0,105 \\
\hline & 2 & 0 & 24,49 & 34,99 & 0,009 & 0,122 \\
\hline & 2 & 0,25 & 39,12 & 58,05 & 0,043 & 0,123 \\
\hline & 2 & 0,5 & 41,67 & 44,44 & 0,017 & 0,169 \\
\hline & 2 & 1,0 & 20,03 & 25,45 & 0,044 & 0,043 \\
\hline & 2 & 2,0 & 34,67 & 37,21 & 0,053 & 0,050 \\
\hline & 2 & 4,0 & 33,72 & 31,79 & 0,061 & 0,279 \\
\hline & 2 & 6,0 & 10,25 & 12,90 & 0,070 & 0,022 \\
\hline \multirow{8}{*}{ NV } & & Natural & 10,09 & - & 0,176 & - \\
\hline & 2 & 0 & 16,86 & 31,49 & 0,0080 & 0,0270 \\
\hline & 2 & 0,25 & 18,77 & 30,06 & 0,0352 & 0,1310 \\
\hline & 2 & 0,5 & 11,29 & 39,42 & 0,0087 & 0,1745 \\
\hline & 2 & 1,0 & 14,31 & 35,56 & 0,0087 & 0,1144 \\
\hline & 2 & 2,0 & 22,11 & 39,92 & 0,0260 & 0,0800 \\
\hline & 2 & 4,0 & 24,56 & 41,58 & 0,0439 & 0,0609 \\
\hline & 2 & 6,0 & 15,25 & 35,64 & 0,0411 & 0,0841 \\
\hline \multirow{8}{*}{ VS } & & Natural & 13,66 & - & 0,507 & - \\
\hline & 2 & 0 & 56,56 & 69,96 & 0,009 & 0,009 \\
\hline & 2 & 0,25 & 33,30 & 46,29 & 0,009 & 0,000 \\
\hline & 2 & 0,5 & 34,98 & 63,61 & 0,044 & 0,000 \\
\hline & 2 & 1,0 & 15,71 & 23,77 & 0,052 & 0,006 \\
\hline & 2 & 2,0 & 9,11 & 17,80 & 0,009 & 0,009 \\
\hline & 2 & 4,0 & 12,25 & 9,43 & 0,009 & 0,009 \\
\hline & 2 & 6,0 & 13,22 & 12,36 & 0,087 & 0,009 \\
\hline
\end{tabular}

Merece destaque o fato de o período de cura máximo adotado neste estudo, para todas as misturas, ter sido de 28 dias. Assim, inferências sobre o comportamento das misturas após este período de cura devem estar substanciadas em nova pesquisa de laboratório, portanto este aspecto situa-se no campo das recomendações futuras para novas pesquisas.

No que se refere à expansão determinada no ensaio CBR, do ponto de vista do projeto e da construção de estradas, os valores observados para os solos ETA, NV e, em menor escala, VS podem ser considerados de pequena representatividade, enquadrando-se mesmo nas exigências de camadas de base granular dos pavimentos rodoviários, pelas recomendações do DNER. No entanto, é de interesse apresentar as alterações introduzidas neste parâmetro pela adição de pelo menos um tipo de alcatrão aos solos e às misturas solo-cal e solo-cimento.

\subsubsection{Resistência à Compressão Simples}

As composições químicas diferenciadas dos alcatrões Mann e Man-170 levaram à ocorrência de respostas mecânicas também diferentes das misturas solo-cal e solocimento, com o alcatrão Mann se mostrando mais efetivo nas misturas solo-cal e o alcatrão Man 170, nas misturas solo-cimento. Destaca-se também que, geralmente, em valores absolutos, as misturas solo-cimento-alcatrão exibem maiores resistências mecânicas. A adição de alcatrão às misturas solo-cal e solo-cimento mostrou-se benéfica para alguns tratamentos, bem como nota-se, em uma visão global, o melhor desempenho do alcatrão

R. Árvore, Viçosa-MG, v.27, n.5, p.657-668, 2003 
Mann-170, seguido do alcatrão Mann. Este fato reforça a necessidade de se proceder à analise do efeito da adição de estabilizantes químicos aos solos, tradicionais ou não, em bases regionais, respeitando-se as particularidades geológicas e pedológicas de cada ocorrência. As composições químicas diferenciadas dos alcatrões Mann e Man170 levaram à ocorrência de respostas mecânicas também diferentes das misturas solo-cal e solo-cimento, com o alcatrão Mann se mostrando mais efetivo nas misturas solo-cal e o alcatrão Man 170, nas misturas solo-cimento. Destaca-se também que, geralmente, em valores absolutos, as misturas solo-cimento-alcatrão exibem maiores resistências mecânicas.

\subsubsection{Comportamento das Curvas Tensão- Deformação das Misturas}

As Figuras de 6 a 8 mostram a variação das propriedades elásticas do solo natural e das misturas, para fins comparativos. Houve substanciais ganhos de resistência à compressão simples, e o comportamento das curvas tensão-deformação obtidas nos ensaios de resistência à compressão simples com a evolução do período de cura das misturas indica estar ocorrendo um processo interno (estabilização), responsável pelo desenvolvimento de ligações de cimentação entre partículas, apresentando as
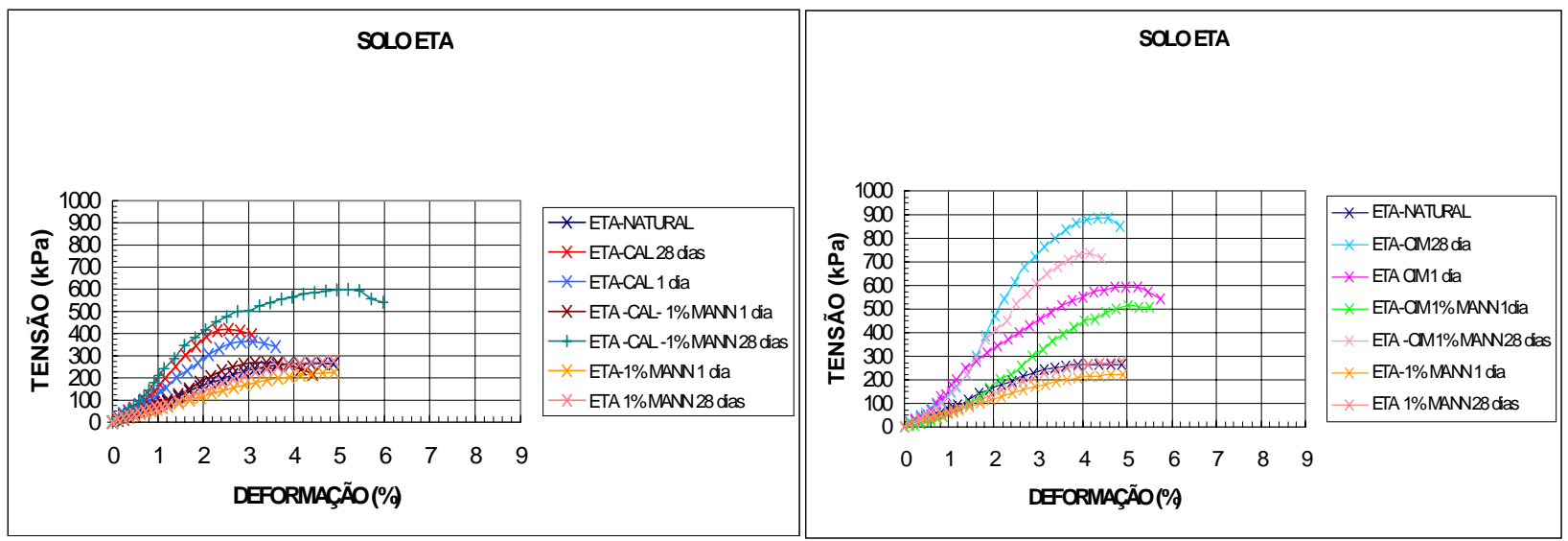

Figura 6 - Curvas tensão-deformação do solo ETA e das misturas ETA-cal e ETA- cimento.

Figure 6 - Tension-deformation curves of ETA soil and ETA-lime and ETA-cement mixtures.
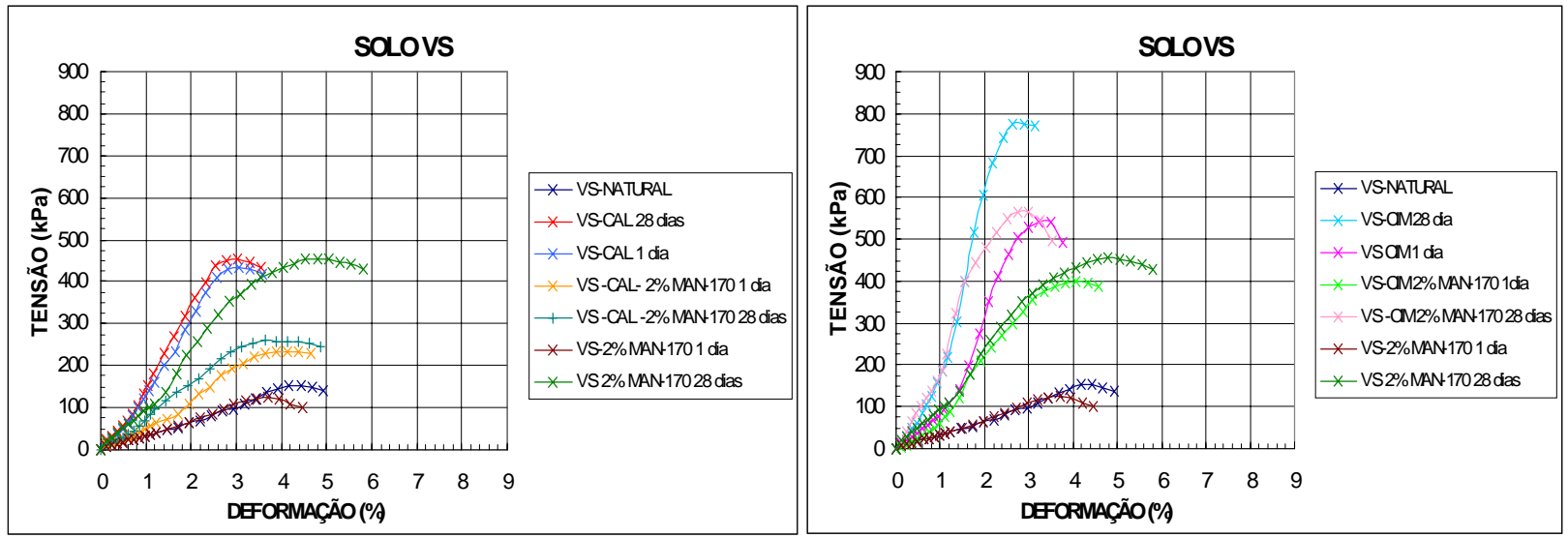

Figura 7 - Curvas tensão-deformação do solo NV e das misturas NV-cal e NV-cimento.

Figure 7 - Tension-deformation curves of $N V$ soil and $N V$-lime and $N V$-cement mixtures. 

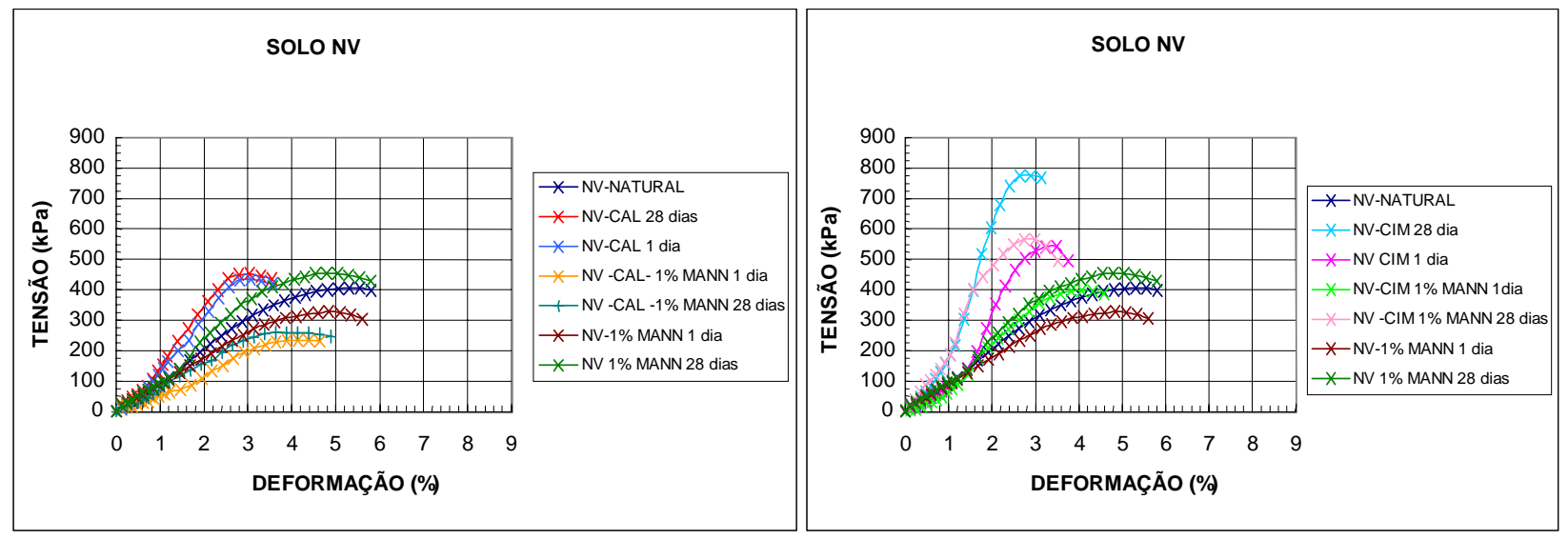

Figura 8 - Curvas tensão-deformação do solo VS e misturas VS-cal e VS-cimento.

Figure 8-Tension-defformation curves of VS soil and VS-lime and VS-cement mixtures.

misturas, marcadamente, comportamento frágil, com significativas mudanças no comportamento elástico.

\subsubsection{Permeabilidade}

Os valores de permeabilidade dos solos naturais são da ordem de $10^{-6} \mathrm{~cm} / \mathrm{seg}$ para os solos ETA e VS, sendo menor para o solo $\mathrm{NV}$, da ordem de $10^{-7} \mathrm{~cm} / \mathrm{seg}$, os quais estão dentro da faixa esperada para amostras destes solos compactadas na energia do ensaio AASHTO Normal (Azevedo, 1999). Houve efeito do período de cura, da dosagem e do tipo de alcatrão sobre os valores de coeficiente de permeabilidade dos solos. Foram constatadas reduções da ordem de $10^{-6}$ para $10^{-7}$ para o solo ETAalcatrão Mann e o solo VS alcatrão Man-170, no período de cura de 28 dias. Esse comportamento pode ser justificado pela penetração do alcatrão nos espaços porosos dos solos ou pela formação de agregados impermeabilizados, o que reduziu a penetração de água no solo. Verificou-se que, em alguns tratamentos, a adição da cal às misturas solo-alcatrão Mann aparentemente não promoveu a floculação das partículas, mantendo assim a porosidade das misturas, o que pode ser comprovado pela tendência de manutenção dos valores de permeabilidade.

\section{CONCLUSÕES}

- O alcatrão agiu diferentemente em cada solo e em cada mistura estabilizada (solo-cal e solo-cimento).
- Houve efeito das dosagens e do período de cura.

- A adição de alcatrão contribuiu para melhorar as características mecânicas e hidráulicas dos solos, não atingindo, entretanto, os padrões de resistência recomendados pelo DNER para camadas de sub-base de pavimentos rodoviários.

- Os três solos em estado natural apresentam CBR de 12,7, 10 e 13,6\%, respectivamente, passando a índices mais elevados $24,7,17,5$ e 40,7\%, nas misturas solocal, e 58, 41,6 e 63\%, nas misturas solo-cimento. A melhoria substancial nos parâmetros de resistência mecânica, provavelmente, foi devido ao fato de a ação cimentante da cal e do cimento ter sido potencializada pelo alcatrão.

- Verificou-se que o alcatrão Mann foi responsável por decréscimos de até dez vezes na permeabilidade dos solo ETA e NV.

- A ação floculante da cal nas misturas solo-cal-alcatrão foi responsável pela elevação da permeabilidade dos solos.

- O alcatrão alterou as características de resistência à compressão simples dos solos. Os melhores resultados obtidos corresponderam às misturas solo ETA com 0,5\% de alcatrão Mann e solo NV com $0,5 \%$ de alcatrão Man-170, no período de cura de 28 dias.

R. Árvore, Viçosa-MG, v.27, n.5, p.657-668, 2003 
- O alcatrão Man-170 melhorou os parâmetros LL e IP, CBR e a compressão simples dos solos.

\section{REFERÊNCIAS BIBILIOGRÁFICAS}

AZEVEDO, M. A. A. Contribuição ao estudo geotécnico de solos de Viçosa-MG. 1999. 169 f. Dissertação

(Mestrado em Geotecnia) - Universidade Federal de Viçosa, Viçosa, 1999.
FERRAZ, R. L. Contribuição ao estudo da estabilização de solos para fins rodoviários e habitacionais. 1994. 180 f. Dissertação (Mestrado em Engenharia Civil) Universidade Federal de Viçosa, Viçosa, 1994.

NOGAMI, J. S.; VILLIBOR, D. F. Pavimentação de baixo custo com solos lateríticos. São Paulo: Vilibor, 1995. $213 \mathrm{p}$.

SENÇO, W. Manual de técnicas de pavimentação. São Paulo: Pini, v.1. 1997. 746 p. 